\title{
Novel thermocouples for temperature measurement in automotive applications
}

\author{
Paul Gierth ${ }^{1}$, Lars Rebenklau', Klaus Augsburg², Eric Bachman², Lars Niedermeyer ${ }^{2}$ \\ ${ }^{1}$ Fraunhofer Institute IKTS, Winterbergstraße 28, D-01277 Dresden, Germany, \\ 2 Technical University IImenau, Gustav-Kirchhoff-Platz 2, D-98693 IImenau, Germany \\ paul.gierth@ikts.fraunhofer.de
}

\begin{abstract}
:
Measurement of temperatures in engine and exhaust systems in automotive applications is necessary for thermal protection of the parts and optimizing the combustion process. State of the art temperature sensors are very limited in their response characteristic and installation space requirement. Miniaturized sensor concepts with a customizable geometry are needed. The basic idea of the novel sensor concept is to use thick film technology on planar and freeform surfaces. Different standardized and especially nonstandard material combinations of thermocouples have been produced for the validation of this technology concept. Application oriented measurement took place in the exhaust system of a test vehicle and were compared to standard laboratory conditions.
\end{abstract}

Key words: thick-film, temperature measurement, automotive applications.

\section{Motivation}

Downsizing of modern engines for automotive application is focusing on efficiency improvement and increasing emission standards. The correlating of performance increase by decreasing engine displacement is often realized with turbo- or superchargers. The thermal management of the engine and exhaust systems gets more difficult by decreasing the component sizes. Many materials are used at their thermal limits. So miniaturized temperature sensors are needed to control and optimize the combustion process and to protect the materials against overheating. The suitability of thick film thermocouples for automotive application could already be demonstrated [1, 2]. Main idea of the present work is to use the sensor application directly on or in thermal stressed engine or exhaust parts. In that way the temperature signals will be generated not just near the interesting areas but rather directly were they are needed to be measured. The possibility to protect thick film thermocouples against harmful surroundings with overglazes is a good possibility to minimize thermal masses of the sensor and in that way helps to improve sensor response times. The following experimental setups and results demonstrate the possibilities of the thick film technology for such sensor applications based on mainly planar substrates but also summarizes the development process for tubular substrates (diameter $>60 \mathrm{~mm}$ for exhaust systems).

\section{Sample preparation}

Thick film thermocouples are designed and produced based on commercially available thick film pastes. The resulting material combinations did not match the standard classification of thermocouples given in DIN EN 60584, because alloys like $\mathrm{NiCr}$ are not fully commercially available as thick film paste. So mainly materials which are typically used for electronic screen printed substrates will be tested as thermocouple materials. In that way a high material availability is given and a fast market introduction phase is guaranteed. The pastes are screen printed with a 325-mesh screen on planar alumina substrates and separately fired in a temperature range between $600-1400{ }^{\circ} \mathrm{C}$ (Fig. 1).

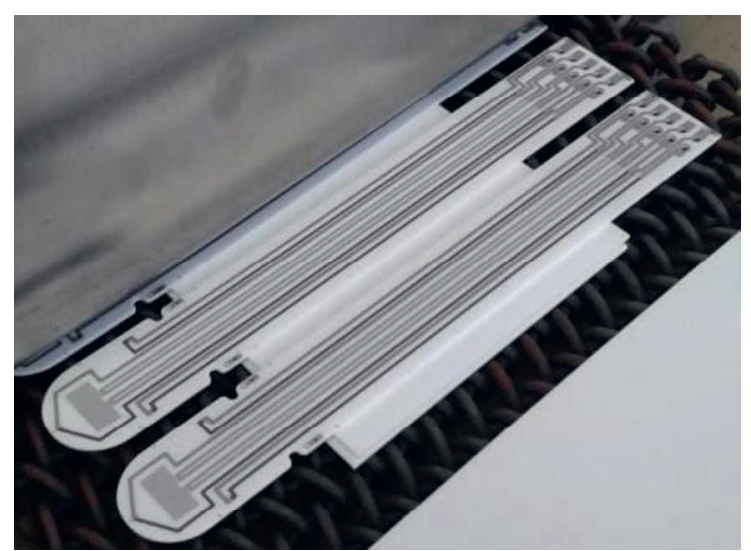

Fig. 1. Firing of thick film thermocouples on alumina substrates. 
Every produced thermocouple has a size of $(200 \times 600 \times 20) \mu \mathrm{m}$ (Fig. 2).

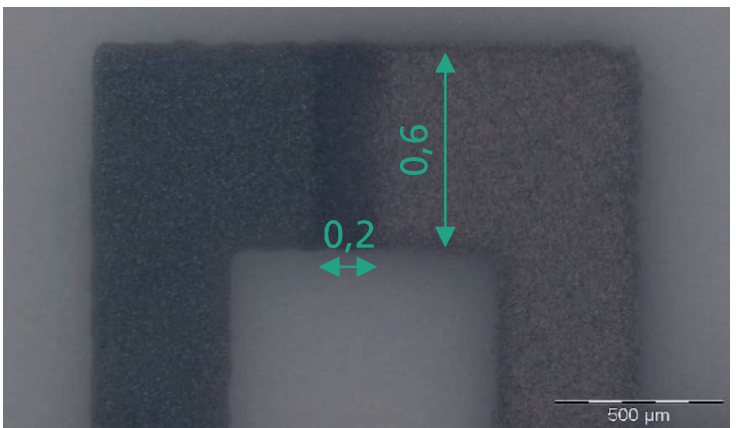

Fig. 2. Microscopy of the miniaturized thick film thermocouple on planar substrates

The printing and firing sequence of the up to four different thick film paste on every substrate needs to take place in decent order of the firing temperature for every material. Platinum or palladium pastes with firing temperature over $1300{ }^{\circ} \mathrm{C}$ were always processed first, followed by the interconnection metallization based on silver/palladium with $850{ }^{\circ} \mathrm{C}$ at last. Firing process takes place for temperatures $>900{ }^{\circ} \mathrm{C}$ in a carbolite HTF1710 and below $900{ }^{\circ} \mathrm{C}$ in a Centrotherm DO4800-125 firing furnace. To generate a standardized thermocouple Typ S a PtRh10 thick film paste has been developed at Fraunhofer IKTS. Therefore, the needed metal powders platinum (90 ma\%) and ruthenium (10 $\mathrm{ma} \%$ ) were homogenized and mixed with an ethyl cellulose-polymer system. The viscosity of this mixture was adjusted with terpineol until it reaches a screen-printable level. Thick film pastes manufacturers are also developing such a paste composition, but this products did not reach fully marked availability until today. The comparison of the ikts thick film composition and a future available commercially product will be given in a future paper.

\section{Experimental}

All samples were evaluated under laboratory and real conditions. Temperatures of the hot and cold end of the thermocouples were validated with platinum thick film Pt100 elements near the thermocouples (fig. 3).

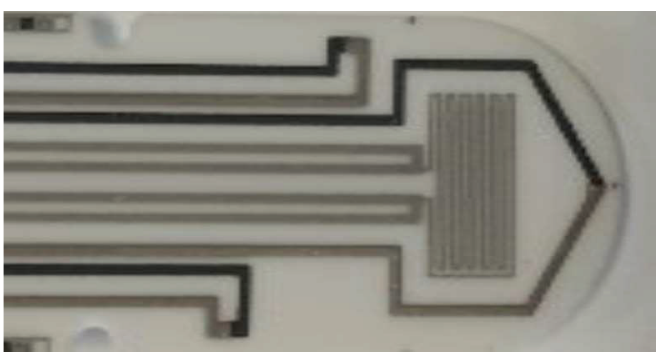

Fig. 3. Sensor layout consisting of three thermocouples and one reference PT100 platinum resistance
This was necessary for the validation of the sensor material, because not all tested thick film pastes can be interconnected with soldering or welding. Therefore, an unformal contact concept as already seen in Fig. 1 has been implanted to guaranty a solderable sensor surface. The consequence is an additional material transition at a different temperature level compared to the screen printed thermocouple. Its influence on the signal quality could be minimized if both contact pads have nearly the same temperature as given in the sensor layout.

Samples were heated in laboratory conditions up to $250{ }^{\circ} \mathrm{C}$ with heating plates. The resulting thermal voltage and the resistances of the PT100 have been measured with Keithley 2700. Seebeck-coefficients in linear thermal voltage correlations to the temperature difference have been calculated for every material combination according eg. (1).

$$
U_{t h}=\int_{T_{1}}^{T_{2}}\left(S_{B}(T)-S_{A}(T)\right) d T
$$

Measurement under real conditions took place in an hot air test rig (fig. 4) and will be further transferred to a test vehicle of the technical university Ilmenau.

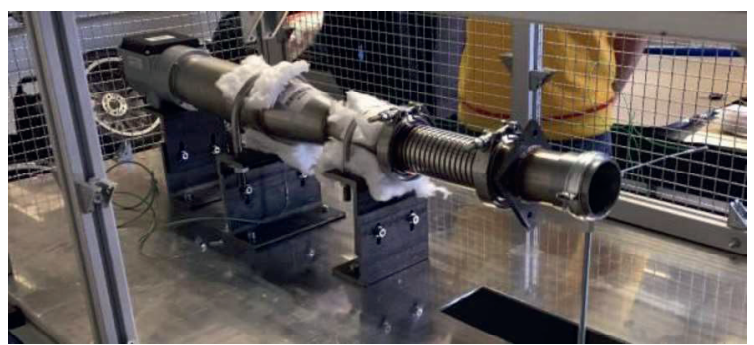

Fig. 4. Hot air exhaust test rig

This vehicle has a high power engine system, which generates high engine and exhaust temperatures caused by its very small overall size. Therefore, temperature sensing is a critical safety system to protect the engine components. For the installation of the sensor elements, a mounting tool was added to the exhaust system (Fig. 5).

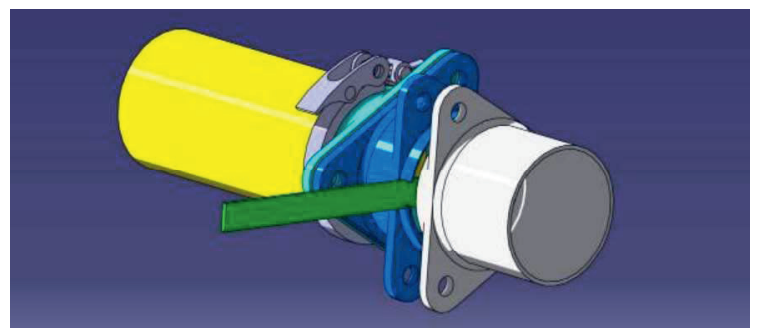

Fig. 5. Mounting system for different thick film thermocouples sensor layouts on planar and tubular substrates 
The mounting tool is prepared for planar substrates as shown in this work and further tubular substrates with thermocouples on their surface. All sensor signals were documented with National Instruments CompactRio measurement system with NI9213 modules.

\section{Results}

Measured thermal voltages in dependence of temperature difference between hot and cold sensor ends are summarized in Fig. 6.

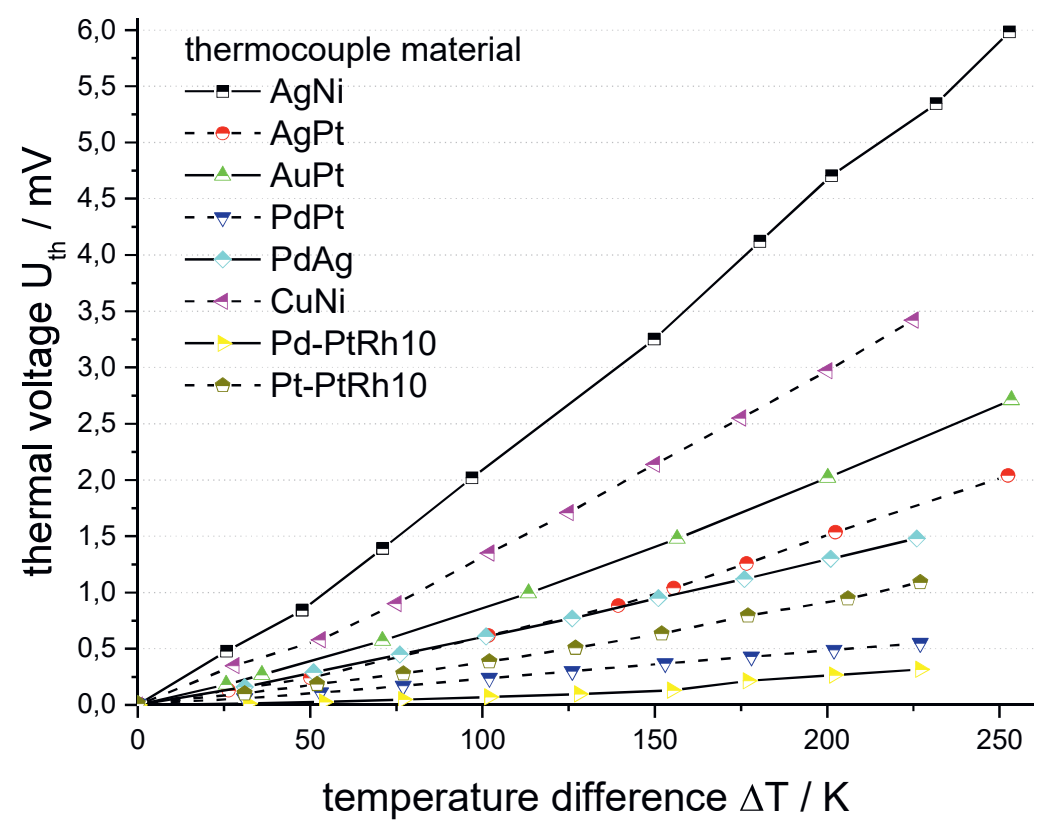

Fig.6. Example of two-columns figure.

All sensor signals are nearly linear up to over $200 \mathrm{~K}$ temperature difference. So the Seebeckcoefficient could be calculated according eg. 1 and is summarized in tab. 1.

Tab. 1: Table caption

\begin{tabular}{|c|c|c|}
\hline material & $\begin{array}{c}\text { Seebeck- } \\
\text { coefficient } \\
\text { in } \mu \mathrm{V} / \mathrm{K}\end{array}$ & $\begin{array}{c}\text { coefficient of } \\
\text { determination } \\
\mathrm{R}^{2}\end{array}$ \\
\hline $\mathrm{AgNi}$ & 23.9 & 0.9956 \\
\hline $\mathrm{AgPt}$ & 8.0 & 0.9799 \\
\hline $\mathrm{AuPt}$ & 10.7 & 0.9912 \\
\hline $\mathrm{PdPt}$ & 2.5 & 0.9976 \\
\hline $\mathrm{PdAg}$ & 6.6 & 0.9982 \\
\hline $\mathrm{CuNi}$ & 15.9 & 0.9959 \\
\hline $\mathrm{Pd}^{2} \mathrm{PtRh}_{10}$ & 1.42 & 0.9086 \\
\hline $\mathrm{Pt} \mathrm{PtRh}_{10}$ & 4.79 & 0.9860 \\
\hline
\end{tabular}

Results are except material combination Pd-PtRh10 comparable to literature values [3]. The thick film sensors were evaluated in the hot air test rig in comparison to standard thermocouples. Exemplary results are shown in fig. 7 .

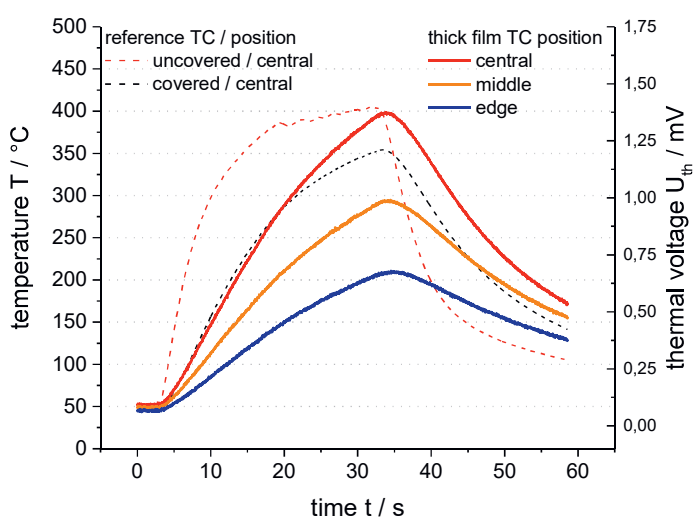

Fig. 7. Mounting system for different thick film thermocouples sensor layouts on planar and tubular substrates

It can be seen, that the thick film thermocouples show good comparability under real conditions. Espacially can be seen the temperature field inside the hot pipe in dependance of the thick film thermocouple position (compare fig. 3). Currently, all promising material combinations are under real condition investigation on ceramic substrates. For the real case of operation, the screen-printing on high temperature stable metallic substrates is necessary. Therefore, an insulation layer 
between the substrate and the electrical sensor elements are highly necessary. Such screen printable glass insulation layers were investigated on different kind of steel substrates (fig. 8). Steels that are in the focus of interest are 1.4828, XSiMo5-1 and NiSiCr35,5.

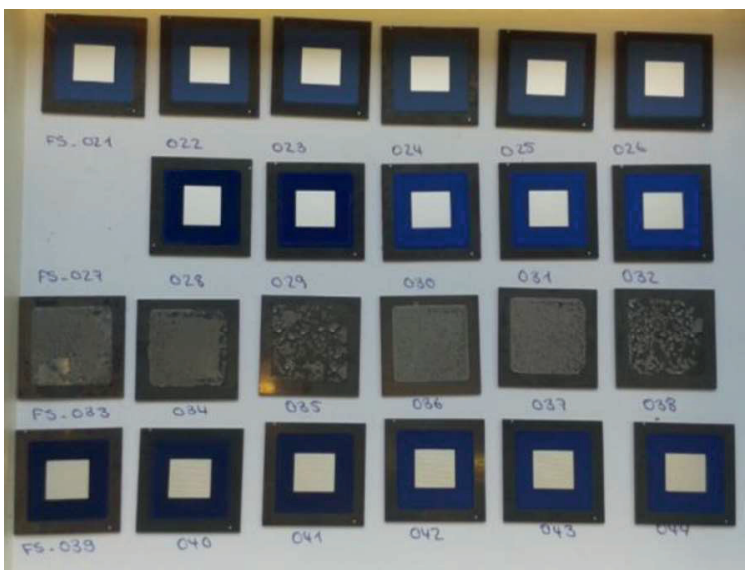

Fig. 8. Screen-printed glass insulation layers on metallic substrates with metallic cover metallization for insulation resistance measurements

Only glass compositions with acceptable adhesion to the substrates were further investigated in terms of insulation resistance. Fig. 9 shows exemplary the insulation resistance of on glass composition on one type of steel for up to $400{ }^{\circ} \mathrm{C}$.

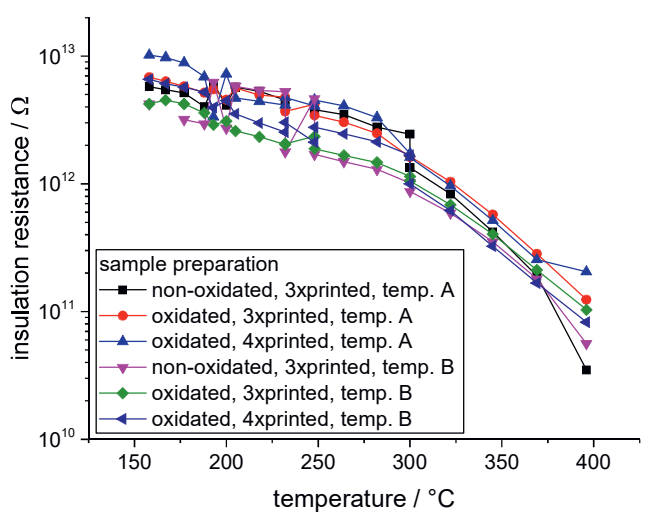

Fig. 9. Insulation resistance of glass insulation of steel substrate

The insulation resistance decreases with increasing temperature this is caused by increasing ionic conductivity. This drastically decrease would also reduce the sensor signal quality especially at high temperature. Therefore, Fraunhofer IKTS developed a novel insulating glass composition, which shows a much higher temperature stability on the industrial relevant stele 1.4828 (fig. 10). The material compatibility of this developed insulation with standard thick film pastes is currently under investigation and will be demonstrated in future works.

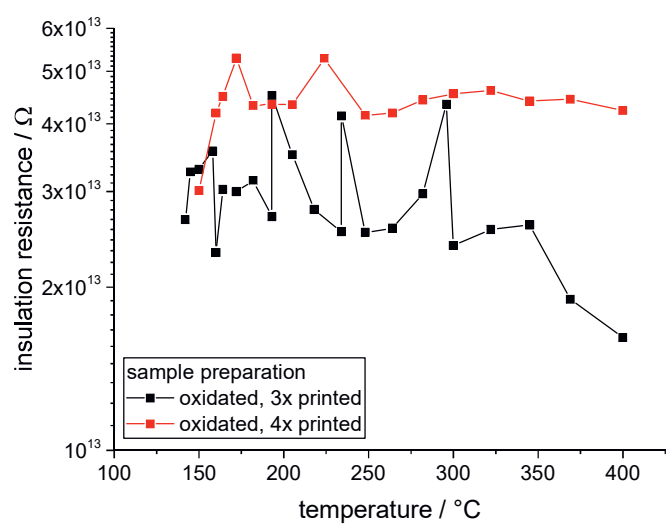

Fig. 10. Insulation resistance of IKTS glass composition on steel 1.4828

Furthermore, the layout transfer from planar to tubular substrates takes place. Therefore, a special screen-printing test rig has been produced at the IKTS (fig. 8). With this system, tubular ceramic and metallic substrates up to diameter of $70 \mathrm{~mm}$ can be surface screenprinted.

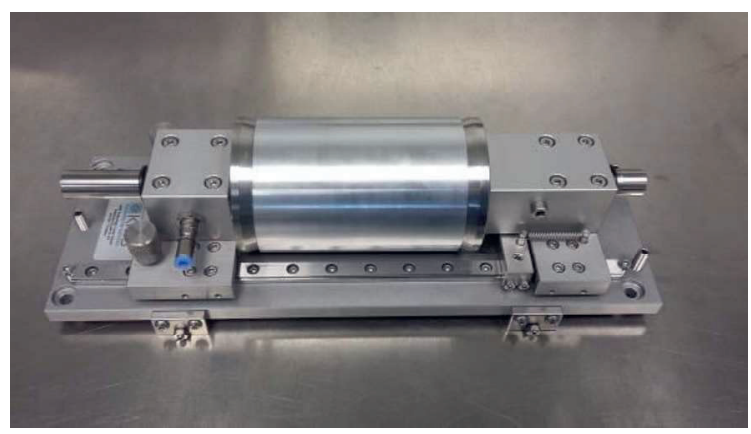

Fig. 8. Tubular screen-printing test rig for tubular substrates with diameter of up to $70 \mathrm{~mm}$

\section{Acknowledgement}

This work was funded by the German Ministry of Education and Research through the Association of German Engineers and association for Electrical, Electronic and Information Technologies (project FreeSenseHT, 03VP00112), which is gratefully acknowledged.

\section{References}

[1] L. Rebenklau, P. Gierth, A. Paproth, K. Irrgang, L. Lippmann, A. Wodtke, L. Niedermeyer, K.

Augsburg, F. Bechtold, European

Microelectronics Packaging Conference (EMPC), 1-5 (2015); ISBN 978-0-9568086-2-2 s

[2] L. Rebenklau, P. Gierth, K. Irrgang, A. Wodtke, K. Augsburg, F. Bechtold, H. Grießmann, L.

Lippmann, L. Niedermeyer, CICMT 2015, 230233 (2015), doi: 10.4071/CICMT-WP14

[3] DIN EN 60584-1: Thermocouples - Part 1, Beuth Verlag, 2013 